\title{
CILDO MEIRELES E A FILOSOFIA DA DIFERENÇA: CARTOGRAFIA DE UM PENSAR CONTEMPORÂNEO EM EDUCAÇÃO
}

\author{
CILDO MEIRELES AND THE DIFERENCE PHILOSOPHY: CARTOGRAPH OF A CONTEMPORARY THINKING IN \\ EDUCATION \\ CILDO MEIRELES Y LA DIFERENCIA FILOSOFÍA: CAROGRAFÍA DE UN PENSAMIENTO CONTEMPORÁNEO EN LA \\ EDUCACIÓN
}

RAMALHO, Ivone Priscilla1

\section{RESUMO}

Este artigo propõe-se a discutir sobre um tipo inventivo de educação numa perspectiva pós-crítica, principalmente por meio das contribuições do filósofo Gilles Deleuze, articulando arte, filosofia e currículo, a partir da obra do artista plástico brasileiro Cildo Meireles. Embasa-se na Filosofia da Diferença e em concepções pós-estruturalistas do currículo, apresentando a obra desse artista conceitual como possibilidade para operar por deslocamentos, para provocar abalos, violências nas formas cristalizadas de pensar a educação. Para isso, utiliza a Cartografia como perspectiva processual de investigação.

Palavras-chave: Filosofia da Diferença. Currículo pós-estruturalista. Arte Conceitual.

\section{ABSTRACT}

This article aims to discuss an inventive type of education in a post-critical perspective, mainly through the contributions of philosopher Gilles Deleuze, articulating art, philosophy and curriculum, based on the work of Brazilian plastic artist Cildo Meireles. It is based on the Philosophy of Difference and poststructuralist conceptions of the curriculum, presenting the work of this conceptual artist as a possibility to operate by displacements, to provoke shaking, violence in the crystallized ways of thinking about education. For this, it uses Cartography as a procedural research perspective.

Keywords: Philosophy of Difference. Poststructuralist curriculum. Conceptual art.

\section{RESUMEN}

Este artículo tiene como objetivo discutir un tipo de educación inventiva en una perspectiva poscrítica, principalmente a través de las contribuciones del filósofo Gilles Deleuze, articulando arte, filosofía y plan de estudios, basado en el trabajo del artista plástico brasileño Cildo Meireles. Se basa en la Filosofía de la Diferencia y las concepciones postestructuralistas del currículum, presentando el trabajo de este artista conceptual como una posibilidad de operar por desplazamientos, provocar temblores, violencia en las formas cristalizadas de pensar sobre la educación. Para esto, utiliza la cartografía como una perspectiva de investigación procesal.

Palabras clave: Filosofía de la diferencia. Currículum postestructuralista. Arte conceptual.

\footnotetext{
${ }^{1}$ Universidade Federal do Rio Grande do Norte - UFRN - Natal - RN - Brasil.
} 


\section{INTRODUÇÃO}

A aproximação das problematizações contemporâneas advindas do campo das artes ainda é pouco explorada no campo da formação docente e do pensamento pedagógico no Brasil. Geralmente, no cenário educacional, a arte é vista a partir de uma perspectiva utilitarista, reduzindo-se à mera utilização de estratégias pedagógicas no campo da educação ou à presença como componente curricular nos programas escolares. Além disso, nas ideias relativas à formação estética prevalece o conceito de estética como contato com 'o belo' ou enfaticamente com a leitura e o aprendizado formais de obras de arte. Posicionando-nos criticamente a essas concepções, apostamos numa experiência estética que provoque desacomodação, desconforto, deslocamento, relacionando-a com processos mais amplos do que a própria arte (LOPONTE, 2017).

Em direções próximas, Perissé (2009) defende uma atitude filosófica que vai além da concepção de estética como contemplação, pois faz-nos pensar detidamente sobre a arte, problematizando-a. O que interessa, nesse caso, é uma estética que deflagre o pensamento, provoque perguntas, sacuda inércias, uma vez que "muito mais do que uma diversão, um passatempo, a arte é função essencial do indivíduo humano e da sociedade, bem como sinal dos nossos inconformismos mais profundos" (p. 28).

Nessa perspectiva, Deleuze e Guattari (2010) concedem destaque à arte como um campo de experimentações e "criação de conceitos", afirmando a maneira própria de "filosofar" da arte por meio dos afectos e perceptos tecidos em seus blocos de sensações. Esta instaura um nível de criação de conceitos tanto quanto a filosofia e a ciência, reconhecidas as suas especificidades, em que é possível constituir uma zona de equivalência entre campos distintos, mas potentes de interlocução. Assim, "criar afectos e perceptos é a maneira de 'filosofar' da arte. Criar conceitos é a maneira de 'fazer arte' da filosofia" (SILVA, 2014, p. 20). Nossa aposta, portanto, é a de que experimentar arte, criar conceitos a partir dos seus afectos e perceptos, não é uma experiência passiva tal como tradicionalmente se pensava em educação. É, ao contrário disso, ser violentado, ser deslocado do nosso próprio modo de pensar.

No contexto educacional, geralmente, predominam-se discursos de práticas homogeneizadoras e cristalizadas, reproduzindo e disseminando padrões, estereótipos, modelos idênticos de ser e estar no mundo, a partir de objetivações de um sistema excludente. Se olharmos pelos ângulos dos moldes tradicionais da escolarização moderna, é muito provável que se perpetue uma educação sem desejos, apetites e sonhos, sendo possível que ela própria se converta em apatia e inércia, onde os sujeitos reproduzem um trabalho tarefeiro e sem sabor, restrito a finalidades mercadológicas.

Diante dessa imposição de ideias fixas, é imperativo cultivarmos brechas, buscarmos linhas de fuga e operarmos por desvios, para experimentarmos um processo criativo de fazer ciência. Nessa tentativa e como uma atitude reativa às queixas e aos desânimos e descontentamentos em relação à educação na contemporaneidade, desejamos incitar um outro modo de pensar sobre as práticas pedagógicas, apostando no deslocamento, na transgressão de fronteiras entre domínios diferentes, no entanto, repletos de interlocução e de inventividade. 
Nesse sentido, este artigo propõe-se a discutir sobre um tipo inventivo de educação numa perspectiva pós-crítica, principalmente por meio das contribuições do filósofo Gilles Deleuze, articulando arte, filosofia e currículo, a partir da obra do artista plástico brasileiro Cildo Meireles. Tratase de operar a arte desse artista como possibilidade de abalar o modo como estamos acostumados a pensar a educação, a pedagogia, o currículo, as políticas educacionais, etc. Isso implica reafirmar a responsabilidade do próprio ato político da pesquisa pós-crítica "em vista do favorecimento de espaços de formação voltados à experimentação artística de um currículo, concebido como a vívida expressão de formas singulares da sensibilidade estética e da criação do novo na educação" (COSTA, 2011, p. 287).

Dessa forma, cabe interrogar: como requerer a arte de Cildo Meireles como potencialização do pensamento em educação? Como ensaiar a perspectiva da arte de Cildo Meireles em seus "blocos de sensações" (DELEUZE; GUATTARI, 2010)? Como relacionar as diferentes linguagens e expressões de sua arte aos processos de construção de currículos? Que deslocamentos a obra desse artista pode provocar nos modos de subjetivação dos indivíduos que vivenciam a educação? Enfim, "O que quer um currículo?", "O que pode um currículo?" (CORAZZA, 2001). Podemos traçar linhas que potencializem modos de chegar a um currículo com a arte de Cildo Meireles e a filosofia? O que pode essa "composição" no território curricular (CORAZZA; SILVA, 2003)?

Para não cair na armadilha de rotular a obra de Cildo Meireles, e posicionando-nos contra qualquer possível tentativa de modelar um processo de educar, lançaremos um olhar sobre a sua obra como um disparador que poderá produzir deslocamentos na nossa própria percepção em torno da educação. Nesse sentido, a arte pode ser operada como pontencialização do pensamento para conceber-se um pós-currículo, a partir de nossas próprias subjetivações no encontro com a sua arte e escrita, uma vez que a obra desse artista "gera certa disposição estratégica para produzir uma força de deslocação que põe o indivíduo no centro político da obra" (SCOVINO, 2009, p. 13).

\section{PERCURSOS CARTOGRÁFICOS: ARTICULAÇÕES ENTRE ARTE CONTEMPORÂNEA, FILOSOFIA DA DIFERENÇA E CURRÍCULO}

No cenário da educação brasileira, as teorias pós-críticas agenciam rupturas e mudanças em relação às pesquisas críticas. Suas produções e invenções têm instaurado práticas educacionais, currículos e pedagogias que caminham para a abertura, a transgressão, a subversão, a multiplicação de sentidos e para a diferença. Não se preocupam com comprovações, nem "revelações" ou "descobertas", pois preferem estar abertas à invenção, à criação e à produção, considerando o sujeito um efeito da linguagem, dos textos, do discurso da história, dos processos de subjetivação. Desse modo, as pesquisas pós-críticas em educação têm feito o currículo e as práticas educativas movimentarem-se. (PARAíSO, 2004).

Ao realizarem investigações que questionam o conhecimento e seus efeitos de verdade e poder, o sujeito e os diferentes modos de subjetivação, os textos educacionais e as diferentes práticas que estes produzem e instituem, essas pesquisas, ao mesmo tempo, expõem as arbitrariedades, os processos de criação, abrindo espaço para criação de novos sentidos em educação. Em suas 
ressonâncias, têm provocado vários deslocamentos. Incita-nos a olhar por múltiplas lentes e a trilhar diferentes caminhos. Possibilita-nos transgredir práticas que, muitas vezes, supomos absolutas e sentidos que nos parecem cristalizados demais. (PARAíSO, 2004).

Dentro dessa perspectiva, acredita-se que "a metodologia deve ser construída no processo de investigação e de acordo com as necessidades colocadas pelo objeto de pesquisa e pelas perguntas formuladas" (MEYER; PARAÍSO, 2012, p. 15). A atividade principal é inventar e ressignificar as questões até então propostas e ir pesquisando em educação sem um método previamente definido a seguir. Ou seja, percebe-se a abertura para inventar o método no próprio ato de criação da pesquisa.

No contexto desses estudos, diferentes pesquisadores/as têm procurado experimentar conceitos e métodos de pesquisas embasados na Filosofia da Diferença (DELEUZE; GUATTARI, 1995, 2010) para discutir temáticas educacionais contemporâneas. Nessa filosofia, o conceito que mais se destaca é o de multiplicidade, que se define "pelo fora; pela linha abstrata, linha de fuga ou de desterritorialização segundo a qual elas mudam de natureza ao se conectarem às outras" (DELEUZE; GUATTARI, 1995, p. 17).

Silva (2014) destaca que esse conceito tem dois objetivos: sublinhar os processos de movimento e de devir, em vez das noções estáticas de essência e de "ser", e permitir pensar a diversidade e a variedade do mundo sem evocar as concepções tradicionais de uno e múltiplo. Nessa direção, "um mundo constituído de multiplicidades é um mundo em movimento contínuo, um mundo de criações" (p. 18).

Gilles Deleuze, filósofo da diferença, entrecruza as fronteiras entre filosofia e arte ou literatura pela própria escrita, em que mistura as mais diversas linguagens. No livro "O que é filosofia?", reafirma a autonomia da filosofia, sem deixar de aproximá-la da arte, ao afirmar que as ciências, as artes, as filosofias são igualmente criadoras. Compreende ainda que a filosofia não é contemplação, nem reflexão, nem comunicação, antes seu objeto é criar conceitos sempre novos, como uma singularidade, quando identifica que "toda criação é singular, e o conceito como criação propriamente filosófica é sempre uma singularidade" (DELEUZE, GUATTARI, 2010, p. 13).

Afirma que a filosofia, assim como a arte, cria. Só que enquanto a arte cria afectos e perceptos, a filosofia cria conceitos. Para Deleuze (2013), "os conceitos não são dados prontos, eles não preexistem: é preciso inventar, criar os conceitos, e nisso há tanta criação e invenção quanto na arte ou na ciência. [...] Um conceito é cheio de uma força crítica, política e de liberdade" (p. 46). Nesse sentido, "o conceito deleuziano passa longe da generalidade que está implicada na compreensão tradicional de conceito. Ele não unifica singularidades ou multiplicidades. Ele as expressa. Não é um transcendente. Ele é imanente à singularidade da qual é extraído" (SILVA, 2014, p. 19-20).

Para Deleuze, o objetivo da arte é "arrancar o percepto das percepções do objeto e dos estados de um sujeito percipiente, arrancar o afecto das afecções, como passagem de um estado a um outro. Extrair um bloco de sensações, um puro ser de sensações" (DELEUZE, GUATTARI, 2010, p. 197). Percebe a obra de arte como um monumento que não comemora um passado, mas é "um bloco de sensações presentes que só devem a si mesmas sua própria conservação, e dão ao acontecimento o composto que o celebra" (DELEUZE, GUATTARI, 2010, p. 198). 
Esse filósofo afirma que o artista acrescenta sempre novas variedades ao mundo, a partir dos seus afectos criadores que podem se encadear ou derivar, em compostos de sensações que se transformam, vibram, se enlaçam ou se fendem. O artista é um criador de afectos, em relação com os perceptos ou visões que nos fornece, fazendo-nos transformar com ele por meio de sua obra. Comparando o artista ao escritor, lança a aposta que ambos podem valer-se dessa fabulação criadora, que excede os estados perceptivos e as passagens afetivas do vivido. (DELEUZE; GUATTARI, 2010).

Criar afectos e perceptos é o modo de "filosofar" da arte. Criar conceitos é o modo de "fazer arte" da filosofia. Se a arte, pois, cria afectos e perceptos (blocos de sensações, agregados sensíveis de cores e linhas, de sons, de imagens, de palavras), que são compatíveis aos conceitos da filosofia, o que faz a filosofia quando pensa a arte? Produz não uma teoria da arte em questão, mas uma teoria dos conceitos daquela arte. O que significa dizer que, de afectos e perceptos, ela extrai conceitos. É justamente o que faz Deleuze, ao se concentrar na análise da produção artística de Francis Bacon, aproximando seus conceitos, suas criações filosóficas, dos afectos e perceptos da pintura de Bacon, de sua criação artística. (SILVA, 2014, p. 20-21).

Em relação à estética, pode-se perceber uma densa produção de Gilles Deleuze dedicada à análise da arte: Francis Bacon: Lógica da Sensação (1981), Cinema-1: a Imagem-Movimento (1983), Cinema-2: a Imagem-Tempo (1985), A Dobra: Leibniz e o Barroco (1988) e O Esgotado (1992). (SILVA, 2014).

É a partir das ideias desse filósofo sobre a potencialidade de hibridização entre domínios diferentes, que percebemos a possibilidade de se deixar entrelaçar arte, filosofia e currículo para criarmos e inventarmos outras maneiras inaugurais e sempre novas em educação, uma vez que "cada elemento criado sobre um plano apela a outros elementos heterogêneos, que restam por criar sobre outros planos: o pensamento como heterogênese" (DELEUZE, GUATTARI, 2010, p. 234-235). Nesse sentido, podemos experimentar um método de pesquisa que provoque deslocamentos, como num processo de desterritorialização, tomando conceitos da filosofia e arte para pensar a educação. Podemos operar deslocamentos a partir da arte de Cildo Meireles, no entrecruzamento com os conceitos da filosofia e estética deleuzianas e as concepções pós-estruturalistas do currículo como possibilidade de provocar abalos, violências nas formas cristalizadas de pensar a educação.

O rizoma, apresentado por Deleuze e Guattari (1995) no livro Mil platôs: capitalismo e esquizofrenia, "não começa nem conclui, ele se encontra sempre no meio, entre as coisas, inter-ser, intermezzo" (p. 36). Essa noção aponta para outras estratégias metodológicas, remetendo-nos ao princípio da Cartografia como perspectiva processual de investigação, principalmente porque o mapa é "aberto, conectável com todas as suas dimensões, demonstrável, reversível, suscetível de receber modificações constantemente. Ele pode [...] adaptar-se a montagens de qualquer natureza, ser preparado por um indivíduo, um grupo, uma formação social" (DELEUZE; GUATTARI, 1995, p. 22).

Segundo Oliveira e Mossi (2014), o rizoma, "para além de um conceito, é também um modelo de pensamento para pensar o próprio pensamento e o modo com que nos deslocamos cognitivamente ante as plurais realidades que atravessamos" (p. 189). Nessa perspectiva, Sílvio Gallo (2013, p. 76-77) explica que o rizoma, por ser aberto, remete-nos a múltiplas possibilidades de pensamento, partindo de seis princípios básicos: princípio de conexão - qualquer ponto de um rizoma pode estar conectado a 
qualquer outro; de heterogeneidade - dado que qualquer conexão é possível; de multiplicidade - é multiplicidade que não pode ser reduzida à unidade; de ruptura assignificante - não pressupõe qualquer processo de hierarquização, estando sempre sujeito às linhas de fuga que apontam para novas e insuspeitas direções; de cartografia - pode ser mapeado, cartografado, e tal cartografia nos mostra que ele possui entradas múltiplas; de decalcomania - degenera, faz florescer, desmancha, prolifera.

Pensar o método a partir do princípio da cartografia faz-nos abrir a pesquisa para o seu processo, acompanhando seu percurso de construção continuamente em movimento e percebendo-a como algo incompleto, transitório e que multiplica as possibilidades e desdobramentos. "A pesquisa, por assim dizer, é sempre um mapa que possibilita múltiplas entradas e onde é possível transitar livremente, agrimensando um terreno em permanente mutação" (OLIVEIRA; MOSSI, 2014, p. 191).

No Brasil, acerca desse método, podemos citar as pesquisas realizadas por Passos, Kastrup e Escóssia (2009), Rolnik (1989) e Fonseca e Kirst (2003), inclinadas para os processos de subjetivação. Nesse sentido, a perspectiva cartográfica corresponde à estratégia que considera mais a trajetória da viagem do que os pontos de partida e/ou chegada, copulando métodos, inventando no decorrer do caminho de acordo com as necessidades instauradas pelo percurso, articulando-as com as intenções da investigação.

Oliveira e Paraíso (2012) atentam para a importância de irrigarmos a pesquisa em educação "com virtualidades desconhecidas para que o já conhecido não vire uma camisa de força, para se criarem muitos modos de pesquisar em educação" (p. 161). Compreendem, com base em Gilles Deleuze, o método da cartografia como uma desterritorialização, que faz estranhar e potencializar os sistemas de pensamento da pesquisa em educação. Nesse caso, cartografar "implica alguma coisa que violenta o pensamento, que o tira de seu natural estupor, de suas possibilidades apenas abstratas" (DELEUZE, 1998 apud OLIVEIRA; PARAíSO, 2012, p. 166). É também "uma operação de traçar linhas de fuga nos territórios, às vezes tão cinzentos, da educação; bailar por entre territórios; abrir-se; [...] enfim, fabular, criar, pintar outros mundos para a educação" (OLIVEIRA; PARAíSO, 2012, p. 167-168).

Nesse sentido, abre-se para aquilo que se encontra geralmente fora do pensado em educação, fazendo com que ela não se torne em outra coisa, mas encontre algo estranho, ainda não pensado (ou pouco pensado) ao habitar algum território de conhecimento que está além do seu domínio: "ora na arte, ora filosofia, em ambas ao mesmo tempo, entre os dois elementos relacionados, naquilo que coexiste e que corre em diferente direção" (RODRIGUES, 2013, p. 172-173).

Dessa forma, a pesquisa pós-crítica constrói conhecimentos que, por mais práticos que sejam, não deixam de ser criações, experimentações. Não formula uma verdade absoluta, mas verdades sempre parciais, e, por isso, os seus resultados encontram-se abertos pelas possibilidades de outras linguagens, que responderão à indagação "O que quer um currículo?", de maneira diferente, múltipla, disseminada.

Ao conceber um currículo como uma linguagem, principalmente por meio das teorias pósestruturalistas, pode-se nas atividades de pesquisa, partir da pergunta: “- o que quer um currículo?". E ao formulá-la, podem-se abrir espaços para que cada pesquisa desdobre-se não sobre "o currículo", como uma resposta única e homogênea. Mas, destacar a expressão "um currículo" como uma 
possibilidade de justificar a multiplicidade de respostas que podem surgir nas investigações. Neste tipo de pesquisa, cada pesquisador/a dá fala a vários "um currículo", tornando a interrogação do desejo um operador metafórico, que requer analisar nossos quereres, fazeres e dizeres constituidores do funcionamento de um currículo. Ou seja, quando parte-se da interrogação "- O que quer um currículo?", cada pesquisador/a dá a sua resposta particular, localizada na rede discursiva das relações de podersaber-subjetividade, que é o que the constitui como linguagem, tornando seu campo discursivo um ato poético, enquanto criação de um domínio específico de objetivação. (CORAZZA, 2001).

Corazza e Silva (2003), inspirados em Gilles Deleuze, atentam para a importância de vivenciarmos agenciamentos sempre novos em educação, que não se trata apenas de uma reunião ou ajuntamento de corpos, mas o que acontece com estes quando se juntam, sob o ponto de vista de seu movimento e de seus mútuos afectos.

\begin{abstract}
Quais são as combinações existentes? Que outras combinações podem ser feitas? E mais importante: quais são as melhores combinações? Quais composições convêm melhor aos diferentes corpos envolvidos? Em geral, um currículo é definido por um conjunto de saberes. Uma pedagogia, por sua vez, estaria na concepção tradicional, fundamentalmente preocupada com a maneira mais eficiente de transmitir esses saberes a um conjunto de aprendizes. E se o currículo, em vez disso, fosse concebido como um encontro, uma composição? Isso não mudaria tudo? Poderíamos começar por imaginar que corpos, os mais improváveis ("sorvete flambado com suspiro"), se encontram e se combinam no currículo, para compor um agenciamentocurrículo particular. (CORAZZA; SILVA, 2003, p. 70).
\end{abstract}

Na pesquisa pós-crítica, é nossa tarefa, como educadores/as, abrir "o campo do social e do político para a produtividade e a polissemia, para a ambiguidade e a indeterminação, para multiplicidade e a disseminação do processo de significação e de produção de sentido" (SILVA, 2010, p. 9). É nesse contexto que podemos destacar a perspectiva pós-estruturalista de currículo, que o enfatiza como prática cultural e como prática de significação (SILVA, 2010). Se partirmos, pois, do entendimento do "currículo como prática de significação, como criação ou enunciação de sentidos, torna inócua distinções como currículo formal, vivido, oculto. Qualquer manifestação do currículo, qualquer episódio curricular, é a mesma coisa: a produção de sentidos" (LOPES; MACEDO, 2011, p. 42).

As teorias pós-críticas alteram radicalmente as concepções de cultura. Os enfoques tradicionais estão assentados numa concepção estática e essencializada de cultura, que corresponde à perspectiva realista e reflexiva do conhecimento. Já na perspectiva pós-crítica, é vista como produção, como criação, em que o currículo passa, então, a ser redefinido como uma prática de significação, uma prática produtiva, uma relação social, uma relação de poder e uma prática que produz identidades sociais. Nesse sentido, tal como a cultura, o currículo é uma zona de produtividade (SILVA, 2010; LOPES, MACEDO, 2011).

Stuart Hall (1997) aponta para cultura como prática de significação, atentando para a sua centralidade nas práticas sociais contemporâneas, uma vez que penetra em cada recanto da vida social, mediando em todos os aspectos e formando nossas identidades sociais. Essa perspectiva de cultura rompe com a ideia de identidade fixa, essencial ou permanente, potencializando as identidades para o que podem vir a se tornar, abrindo espaço para os processos contínuos de transformações que permeiam o sujeito pós-moderno. "A identidade torna-se uma celebração móvel: formada e 
transformada continuamente em relação às formas pelas quais somos representados ou interpelados nos sistemas culturais que nos rodeiam. É definida historicamente, e não biologicamente" (HALL, 2005, p. 12-13).

Num mundo instável, as identidades também se tornam instáveis, híbridas e deslocadas de um vínculo local. "E isso significa também que são transformadas em uma tarefa individual, em um processo de construção incessante, e não mais de atribuição coletiva que provocava apenas certa conformação às normas sociais" (MOCELLIM, 2008, p. 2). É a partir dessas ideias que consideramos relevante a opção por trabalhar com o método da cartografia, principalmente por permitir a interlocução entre distintas áreas do saber, especificamente, no campo do currículo com a arte e a filosofia, levando em consideração que esse entrecruzamento é uma forma rizomática de produzir saberes, não obedecendo a relações subordinadas ou hierárquicas. Assim, essa perspectiva dá abertura para que o pesquisador opere por deslocamentos, siga construindo, inventando e reinventando no próprio ato de pesquisar, enfatizando-o em sua dimensão política.

Isso vai ao encontro de Deleuze (2013) que considera esse tipo de pesquisa algo que abriga riscos e incertezas, uma vez que opera o pensamento pelo "fora". É assim que este artigo posiciona-se, como algo "fora" do que já foi pensado em educação, no entanto disponível para inventar e criar outros modos de pensar, com novas e inusitadas virtualidades.

\footnotetext{
No momento em que alguém dá um passo fora do que já foi pensado, quando se aventura para fora do reconhecível e do tranquilizador, a fim de inventar novos conceitos para terras desconhecidas, caem os métodos e as morais, e pensar torna-se, como diz Foucault, um "ato arriscado", uma violência que se exerce primeiro sobre si mesmo". (DELEUZE, 2013, p. 132).
}

Tal maneira de assumir a pesquisa instaurando novos olhares sobre a educação comunga com o que pensa George Steiner (1990) quando afirma que "o artista e o escritor são turistas incessantes olhando as vitrines de todo o âmbito das formas disponíveis" (p. 27). Ainda nessa perspectiva, Bauman (2005) traz à tona o pensamento desse crítico cultural que apontou Samuel Beckett, Jorge Luis Borges e Vladimir Nabokov como os mais importantes escritores contemporâneos, percebendo que o que os colocavam numa posição de destaque era o fato de serem polímatas linguísticos, capazes de movimentar com facilidade em vários universos linguísticos diferentes.

\section{DESLOCAMENTOS NA ARTE DE CILDO MEIRELES}

Deixar-se afetar pelas provocações do artista plástico Cildo Meireles, operando por deslocamentos para o campo educacional, é um ato que se faz em percursos cartográficos, compreendendo que "cartografar é acompanhar um processo e não representar um objeto" (KASTRUP, 2008, p. 469). Essa estratégia atua sob uma perspectiva não prescritiva, possibilitando acompanhar processos que são da ordem do invisível e do plano das sensações (PASSOS; BARROS, 2009). Nesse sentido, cabe aqui cartografar um tipo inventivo de pensar sobre as práticas educacionais contemporâneas a partir das instalações desse artista. 
Influenciado por Marcel Duchamp, que recolocou as artes plásticas não mais no plano da discussão tecnológica, mas no plano da discussão filosófica, Meireles (2009) afirma que um dos papeis da arte é o de "interferir no processo social da comunidade, deflagrando, através de suas obras, determinados comportamentos, mesmo que elas não sejam retidas em sua forma original" (p. 37-38).

Cildo Meireles é um artista conceitual pioneiro no Brasil, que concebeu uma arte radical. Sua obra sempre privilegiou a circulação da informação como um ato político de comunicação. Suas instalações e propostas tendem a um embate com o campo institucional e mercadológico, ao mesmo tempo em que se relacionam com o espectador. A construção matemática de seu trabalho, em que os mesmos elementos se alternam em progressão geométrica, investe num deslocamento de perspectiva e assim explora também com o corpo. Esse artista mostra-se coerente com a trajetória que traçou para si, na qual convive um caráter pessoal reservado, uma obra inquieta, de resistência política (SARDENBERG, 2011, p. 99).

A arte conceitual, expandida na década de 1970, foi marcada por um amplo repertório de experimentações. Concebe-se a arte como ideia, operando com o corpo em performances, com novos meios tecnológicos, multimeios e uma outra modalidade espacial e fragmentada de trabalho Instalação. O que marca essa arte nesse período é a revitalização do pensamento de Marcel Duchamp, que defendia a arte como um gesto resultante de um pensar, na qual os artistas são vistos como criadores-operadores de ideias. Como vertente idealista, a arte conceitual gera "aparelhos de significados", como Duchamp definira anteriormente os ready-mades - objetos retirados do cotidiano, e representados como elementos do processo criativo (PECCININI, s/r).

Dessa forma, o posicionamento político de Cildo Meireles em relação à arte permite-nos perceber a sua obra como um "operador metafórico" de um pós-currículo (CORAZZA, 2001).

\begin{abstract}
Se analisarmos a obra de Cildo como um mapa, sua cartografia é um processo de múltiplas entradas em territórios descontínuos. Em seus textos, percebemos que essa é sua estratégia para a desconstrução das certezas do mapa e emergência de sua estética. Sua obra tece memória afetiva, vivências culturais, cultura de massa, conhecimento científico e consciência crítica da história e da arte. (SCOVINO, 2009, p. 15).
\end{abstract}

Uma série de trabalhos de Cildo Meireles demonstra a estratégia de sua arte como ativismo político. Podemos citar, como exemplo, "Inserções em circuitos ideológicos", cujo objetivo era criar um sistema de circulação e troca de informação que vaza do controle centralizado. Essa obra teve grande influência no contexto histórico em que se propagou, a ditadura militar de 1964. Assim, o artista procurava explorar alternativas para travar uma guerrilha contra o sistema repressor daquele período, transmitindo informações por uma variedade de circuitos alternativos, como garrafas de Coca-Cola e cédulas de dinheiro (BRAGA, 2015). Essa postura de esquerda perante o sistema faz-nos pensar sobre o nosso papel enquanto educadores, no sentido de demonstrar luta e resistência em tempos de opressão e controle. Inventar outras formas de educar, de interagir com os estudantes, de produzir conhecimento, que extrapolem os mecanismos de controle impostos pelo poder central. No campo político, um pós-currículo situa-se à esquerda, em que os seus conceitos e critérios possuem potencial e carga políticas (CORAZZA, 2010). 
Esse currículo combativo assinala a premência de discutir e produzir políticas e práticas curriculares contra-hegemônicas às dimensões utilitárias, instrumentais e econômicas da educação neoliberal. Empenha suas forças produtivas e contestatórias na formulação de muitos currículos culturais, como forma de luta social, que ampliem as possibilidades solidárias, populares e democráticas, que não mais silenciem ou marginalizem os diferentes. Faz isso, historicizando, politizando e culturalizando todos os currículos já construídos pela maioria das populações e inventando novos e ousados arranjamentos curriculares. (CORAZZA, 2010, p. 107).

Em "Sal sem carne", Cildo Meireles problematiza as tensas relações que se desenrolaram entre comunidades indígenas e colonizadores no Brasil, deflagrando a violência contra os índios, evocando questões ideológicas, restrições étnicas, enfim, o gueto, que é lugar de invisibilidade territorial, política e cultural. O gueto assume "a característica de ser uma criação social para a dinâmica da exclusão do outro e, ao se impor, gerar, para os que nele habitam, a energia necessária à consequente superação de situações de marginalização" (GRANDO, 2016, p. 5).

Nessa instalação, o artista conceitual resgata o massacre dos índios krahôs, ocorrido em 1940 na cidade de Trindade-GO, envolvendo, em seu espaço expositivo, uma série de inserções intercambiantes por meio de artefatos sonoros e visuais. Um vinil com gravações de vozes e palavras sobrepostas, com sonoridades híbridas entre portugueses e indígenas, que ecoam junto ao aparato visual de sua capa e contracapa exposto na parede. Nesse espaço copula, ainda, um cabide amarelo de madeira suspendendo vários monóculos azuis e vermelhos, contendo fotografias de índios krahôs, incluindo a de um sobrevivente do massacre. (GRANDO, 2016; PARENTE, 2019).

A intenção do artista de colocar o que está à margem no centro, questionando os discursos hegemônicos, dando visibilidade a grupos silenciados, provocando, instigando o pensamento ao que é diferente, denunciando problemas sociais que ainda são latentes na contemporaneidade, pode disparar quereres em inventar um currículo aberto para "as dinâmicas da diferença e as experiências inquietantes da alteridade" (CORAZZA, 2010, p. 106), onde nossa tarefa principal seja lutar contra a discriminação e estereotipação do outro, escutando o que os diferentes têm a dizer e incorporando, em seu corpus, as diferenças.

Segundo Skliar (2010), o outro é um ser inventado, que quase sempre vem mascarado, designado, emudecido, fixado, constituído em um simples ventríloquo de nossa mesmice, transformado em uma espacialidade exterior da nossa (in)diferença. E, como pensar o outro sem nos deixarmos cair nessas armadilhas que mascaram nosso próprio olhar, sem lançarmos um olhar reduzido/simplificado? Um primeiro passo se faz necessário no sentido de reconhecer que há uma política, uma poética e uma filosofia das diferenças.

\footnotetext{
Já não é, então, a relação existente entre nós e eles, entre a mesmice e a alteridade, o que define a potência existencial do outro, mas a presença - antes ignorada, silenciada, aprisionada etc. - de diferentes espacialidades e temporalidades do outro; já não se trata de identificar uma relação do outro como sendo dependente ou como estando em relação empática ou de poder com a mesmice; não é uma questão que se resolve enunciando a diversidade e ocultando, ao mesmo tempo, a mesmice que a produz, define, administra, governa e contém; não se trata de uma equivalência culturalmente natural; não é uma ausência que retorna malferida; trata-se, por assim dizer, da irrupção (inesperada) do outro, do ser-outro-que-é-irredutível-em-sua-alteridade. (SKLIAR, 2010, p. 205).
}

Ao compreender a educação como um processo inacabado, Skliar (2010) propõe a educação como poiesis, que quer dizer, como um tempo de criatividade e de criação que não pode nem se quer 
orientar para o mesmo, para a mesmice. Dessa forma, que possamos, a partir das provocações da arte de Cildo Meireles, desvanecer-nos para criar uma outra pedagogia e várias outras. Pedagogias do acontecimento, descontínuas, que provoquem o pensamento, que retirem do espaço e do tempo todo saber já disponível, consagrado; que nos faça recomeçar sempre, que faça da mesmice um pensamento insuficiente para dizer, sentir, compreender aquilo que tenha acontecido; que emudeça a mesmice. (SKLIAR, 2010).

Em direções próximas, Corazza (2010) incita-nos a celebrar um pós-currículo da diferença, que pode ser todos os currículos que nos sentimos convocados a criar, potentes para provocar outros pensamentos. Um currículo cultural, em situação contínua de luta social, politicamente engajado em problemas sociais, considerando-se uma "prática teórico-investigativa e, ao mesmo tempo, uma prática ativa de transformação cultural, imersa em relações de poder-saber, particularidades de subjetividades multiculturais e multirraciais" (p. 108). Que possamos, portanto, assumir eticamente os ricos e errâncias da produção de vários outros currículos da diferença.

\section{CONSIDERAÇÕES FINAIS}

Instaurar um currículo pós-crítico articulado à arte conceitual de Cildo Meireles e à filosofia da diferença abre o campo educacional para movimentar o pensamento, cultivando brechas, buscando linhas de fuga, operando por desvios e deslocamentos, como possibilidade de produzir outros sentidos a partir das problematizações que as obras desse artista provocam, uma vez que questionam os discursos hegemônicos que circulam nas práticas sociais contemporâneas.

Assim, ao cartografar uma experimentação estética e invenção do pensamento por meio dos afectos e perceptos que as instalações desse artista nos causam, percebemos que tal empreendimento atuou como uma potente estratégia para produzir deslocamentos na nossa própria percepção em torno da educação, no que se refere ao nosso posicionamento político enquanto educadores, no qual instiganos a criar uma pedagogia e várias outras, de luta e resistência aos mecanismos de controle, de abertura para dialogar com as diferenças, dando visibilidade a grupos e vozes silenciados nas práticas curriculares.

\section{REFERÊNCIAS}

1. BAUMAN, Zygmunt. Identidade: entrevista a Benedito Vecchi. Tradução de Carlos Alberto Medeiros. - Rio de Janeiro: Jorge Zahar Editora, 2005.

2. BRAGA, Eduardo Cardoso. Cildo Meireles, arte conceitual e política: um Duchamp reverso. In: Concept - Academic Philosophy: Art, Design and Communication, out/2015. Disponível em: http://www.edubraga.pro.br/art-design-environmental-art-land-art-performance-art-povera-art/cildomeireles-arte-conceitual-e-politica-um-duchamp-reverso/. 
3. CORAZZA, Sandra Mara. Diferença pura de um pós-currículo. In: LOPES, Alice Casimiro; MACEDO, Elizabeth (Orgs.). Currículo: debates contemporâneos. - 3 ed. - São Paulo: Cortez, 2010.

4. O que quer um currículo?: pesquisas pós-críticas em Educação. - Petrópolis, RJ: Vozes, 2001.

5. CORAZZA, Sandra Mara; SILVA, Tomaz Tadeu da. A arte do encontro e da composição: Spinoza + Currículo + Deleuze. In: Composições. - Belo Horizonte: Autêntica, 2003.

6. COSTA, Gilcilene Dias da. Curricularte: experimentações pós-críticas em educação. In: Revista Educação e Realidade, Porto Alegre, v. 36, n. 1, p. 279-293, jan/abr., 2011.

7. DELEUZE, Gilles. Conversações. Tradução de Peter Pál Pelbart. 3 ed. - São Paulo: Editora 34, 2013.

8. DELEUZE, Gilles; GUATTARI, Félix. Mil platôs: capitalismo e esquizofrenia - vol. 1. Tradução de Aurélio Guerra Neto e Célia Pinto Costa.- Rio de Janeiro: Editora 34, 1995. O que é Filosofia?. Tradução de Bento Prado Jr. E Alberto Alonso Muñoz. 3 ed. - São Paulo: Editora 34, 2010.

10. FONSECA, Tânia Maria Galli; KIRST, Patrícia Gomes (Orgs.). Cartografias e devires: A construção do presente. Porto Alegre: Editora da UFRGS, 2003.

11. GALLO, Sílvio. Deleuze \& a Educação. - 3 ed. - Belo Horizonte: Autêntica Editora, 2013.

12. GRANDO, Ângela. Sal sem carne - para uma estética do gueto. In: Artelogie, 8/2016. Disponível em: https://journals.openedition.org/artelogie/496.

13. HALL, Stuart. A centralidade da cultura: notas sobre as revoluções culturais do nosso tempo. In: Revista Educação e Realidade, v. 22, jul/dez, 1997.

14. HALL, Stuart. A identidade cultural na pós-modernidade. 10 ed. - Rio de Janeiro: DP\&A Editora, 2005.

15. KASTRUP, V. O método da cartografia e os quatro níveis de pesquisa-intervenção. In: CASTRO, L. R. de; BESSET, V. L. (orgs.). Pesquisa-intervenção na infância e juventude. Rio de Janeiro: Trarepa/FAPERJ, 2008. 
LAPONTE, Luciana Gruppelli. Tudo isso que chamamos de formação estética: ressonâncias para a docência. In: Revista Brasileira de Educação, v. 22, n. 69, abr/jun, 2017.

LOPES, Alice Casimiro; MACEDO, Elizabeth. Teorias do Currículo. - São Paulo: Cortez, 2011

18. MEIRELES, Cildo. Encontros. (Organização de Felipe Scovino). - Rio de Janeiro: Beco do Azouge, 2009.

19. MEYER, Dagmar Estermann; PARAíSO, Marlucy Alves (Orgs.). Metodologias de pesquisas póscríticas em educação. Belo Horizonte: Mazza Edições, 2012.

20. MOCELLIM, Alan. A questão da identidade em Giddens e Bauman. In: Revista Eletrônica dos PósGraduandos em Sociologia Política da UFSC, v. 5, n. 1, ago/dez, 2008.

OLIVEIRA, Marilda Oliveira de; MOSSI, Cristian Poletti. Cartografia como estratégia metodológica: inflexões para pesquisas em educação. In: Revista Conjectura: Filosofia e Educação. - Caxias do Sul, v. 19, n. 3, p. 185-198, set/dez, 2014.

OLIVEIRA, Thiago Ranniery Moreira de; PARAíSO, Marlucy Alves. Mapas, dança, desenhos: a cartografia como método de pesquisa em educação. In: Revista Pro-posições, v. 23, n. 3, p. 159178, set/dez, 2012.

23. PARAíSO, Marlucy Alves. Pesquisas pós-críticas em educação no Brasil: esboço de um mapa. In: Cadernos de Pesquisa, v. 34, n. 122, p. 283-303, maio/ago, 2004.

24. PARENTE, Alessandra. Conhecer pode ser destruir. In: Revista Cult, 7 de outubro de 2019. Disponível em: https://revistacult.uol.com.br/home/cildo-meirelles-entrevendo/

25. PASSOS, Eduardo; KASTRUP, Virgínia; ESCÓSSIA, Liliana da. Pistas do método cartográfico: Pesquisa-intervenção e produção de subjetividade. Porto Alegre: Editora Sulinas, 2009. PECCININI, Daisy. Arte conceitual, instalação e multimeios anos 70 . Disponível em: http://www.mac.usp.br/mac/templates/projetos/seculoxx/modulo5/multimeios.html.

PERISSÉ, Gabriel. Estética e Educação. - Belo Horizonte: Autêntica Editora, 2009.

RODRIGUES, Carla Gonçalves. Currículo movente constituindo forma na ação docente. In: CLARETO, Sônia Maria; FERRARI, Anderson. Foucault, Deleuze e Educação. 2 ed. ampliada e revisada. - Juiz de Fora: Editora UFJF, 2013. 
29. ROLNIK, Suely. Cartografia sentimental: transformações contemporâneas do desejo. São Paulo: Estação Liberdade, 1989.

30. SARDENBERG, Ricardo. Arte contemporânea no século XXI: 10 brasileiros no circuito internacional. - Rio de Janeiro: Capivara, 2011.

31. SCOVINO, Felipe. Redes, tramas e afins. In: MEIRELES, Cildo. Encontros. (Organização de Felipe Scovino). - Rio de Janeiro: Beco do Azouge, 2009.

32. SILVA, Tomaz Tadeu da. O currículo como fetiche: a poética e a política do texto curricular. 1 ed. Belo Horizonte: Autêntica Editora, 2010.

33. SILVA, Tomaz Tadeu da. Tinha horror a tudo que apequenenava... In: AQUINO, Julio Groppa; REGO, Teresa Cristina (Orgs.). Deleuze pensa a educação: A docência e a filosofia da diferença. São Paulo: Editora Segmento, 2014. (e-book).

34. SKLIAR, Carlos. A educação que se pergunta pelos outros: e se o outro não estivesse aqui? In: LOPES, Alice Casimiro; MACEDO, Elizabeth (Orgs.). Currículo: debates contemporâneos. - 3 ed. São Paulo: Cortez, 2010.

35. STEINER, George. Extraterritorial: A literatura e a revolução da linguagem. Tradução de Júlio Castañon Guimarães. - São Paulo: Companhia das Letras, 1990.

Ivone Priscilla Ramalho

Pedagoga e Mestre em Educação (Universidade Federal do Rio Grande do Norte) Professora substituta do Departamento de Práticas Educacionais e Currículo da Universidade Federal do Rio Grande do Norte Professora de Educação Infantil da Prefeitura Municipal de Parnamirim-RN.

Como citar este documento:

RAMALHO, Ivone Priscilla. Cildo Meireles e a Filosofia da Diferença: Cartografia de um pensar contemporâneo em educação. Reflexão e Ação, Santa Cruz do Sul, v. 28, n. 2, jun. 2020. ISSN 19829949. Disponível em: <https://online.unisc.br/seer/index.php/reflex/article/view/14313>. Acesso em: . doi:https://doi.org/10.17058/rea.v28i2.14313. 